\title{
Fractional order PID sliding mode control for speed regulation of permanent magnet synchronous motor
}

\author{
Fardila Mohd Zaihidee*,**, Saad Mekhilef*,***,**** and Marizan Mubin**** \\ *Power Electronics and Renewable Energy Research Laboratory, Department of Electrical Engineering, Faculty of Engineering, University of \\ Malaya, 50603 Kuala Lumpur, Malaysia \\ **Faculty of Technical and Vocational, Sultan Idris Education University, 35900 Tanjong Malim, Perak, Malaysia \\ ***School of Software and Electrical Engineering, Faculty of Science, Engineering and Technology, Swinburne University of Technology, \\ Victoria, Australia \\ ****Department of Electrical Engineering, Faculty of Engineering, University of Malaya, 50603 Kuala Lumpur, Malaysia \\ ****Corresponding Authors: marizan@um.edu.my,saad@um.edu.my,fardila@ftv.upsi.edu.my
}

$\begin{array}{ll}\text { Submitted: } & 09 / 12 / 2019 \\ \text { Revised: } & 12 / 11 / 2020 \\ \text { Accepted: } & 23 / 11 / 2020\end{array}$

\begin{abstract}
This paper proposed a fractional order PID sliding mode control (FOSMC-PID) for speed regulation of permanent magnet synchronous motor (PMSM). Fractional calculus has been incorporated in sliding mode controller (SMC) design to enhance chattering suppression ability. However, the design of fractional sliding surface is crucial to ensure that speed tracking accuracy is not jeopardized. The proposed controller is designed with a fractional order PID sliding surface, which balances the characteristics of sliding surface with PI or PD structure in terms of robustness and dynamic performance of the controller. By simulation, speed tracking is proven to be faster and more robust with the proposed controller compared to SMC with integer order. Both integration and derivative terms in the surface design outperform FOSMC-PI and FOSMC-PD in terms of disturbance rejection and chattering. Experimental validation proves the advantage of the proposed controller in terms of robustness.
\end{abstract}

Keywords: Fractional calculus; Permanent magnet synchronous motor; Sliding mode control; Speed regulation.

\section{INTRODUCTION}

Permanent magnet synchronous motors (PMSM) are one type of AC machines, which have similar stator construction as in induction motors and similar field excitation concept as in brushless DC (BLDC) motor but have back-EMF of sinusoidal type. The rotor consists of permanent magnets, which generate a substantial air gap magnetic flux. PMSM are widely used in high performance drives such as machine tools, electric vehicles, and robotics due to their high efficiency, high power density, high air-gap flux density, and high torque to inertia ratio. Other than that, they are compact in structure and require low maintenance compared to brush-type motors. However, nonlinear time-varying parameters and complex dynamics of PMSM system create challenge in their control development. Conventional PI control technique, which performs excellently in systems with precise modeling, cannot guarantee accurate control of PMSM system. Various modern controllers have been developed to realize high performance and robust control of PMSM such as predictive (Errouissi, Ouhrouche, Wen-Hua, \& Trzynadlowski, 2012), backstepping (Zhou \& Wang, 2002), adaptive (Vu, Choi, \& Jung, 2012), Hळ (Hsien, Sun, \& Tsai, 1997), active disturbance rejection control (ADRC) (Su, Zheng, \& Duan, 2005), and artificial intelligence (AI) controllers (Han Ho \& Jin-Woo, 2013). However, wide application of these controllers is limited due to their complexity (Wang, Jia, \& Dong, 2013). 
SMC is known for its robustness, high accuracy, and simplicity. It can guarantee reference tracking even for systems with internal parameter uncertainties and external disturbances. However, major drawback of SMC is chattering issue caused by frequent switching and parasitic dynamics interactions (Shihua, Mingming, \& Xinghuo, 2013). It can reduce control accuracy, cause high heat loss in electrical circuits, and damage mechanical parts (Utkin, 1993). Therefore, significant reduction of chattering phenomenon in SMC is crucial in order to obtain an accurate and robust control. Suppression of chattering is challenging since methods introduced to do so can affect controller's robustness.

Enhancement in SMC focuses on proposing methods to improve both disturbance rejection and chattering reduction properties of the designed controller. Reaching law method is used to minimize chattering at the end of reaching phase. For speed control of PMSM, several novel reaching laws have been proposed (Xiaoguang, Lizhi, Ke, \& Li, 2013; X. Zhang, Zhao, \& Sun, 2011). However, modification of control law in this approach can affect speed tracking in terms of steady-state error and reaching time (Xiaoguang et al., 2013). In conventional SMC, total disturbance rejection happens when switching gain value is bigger than upper bound of disturbances. The upper bound is hard to be obtained practically; hence, the switching gain is normally selected to be high to ensure complete disturbance rejection. High gain results in large chattering in SMC. To overcome this issue, disturbance compensation is incorporated with SMC. Instead of lumped disturbances, the SMC works with only the disturbance compensation error, which allows selection of smaller gain and contributes in reducing chattering (Shihua Li, Kai Zong, \& Huixian Liu, 2011). For PMSM applications, two disturbance estimation techniques are widely used with SMC, namely, disturbance observers (Xu, Jiang, \& Mu, 2016) and extended state observers (Xu, Junejo, Liu, \& Islam, 2019). The performance of composite SMC with disturbance compensator depends on accuracy and speed of estimation algorithm used. Furthermore, compensator's parameter must be carefully selected, so that overall controller's stability is ensured. Another method of SMC enhancement is incorporation of artificial intelligence (B. Zhang, Pi, \& Luo, 2012). Among the disadvantages of this method are tedious programming required, complicated parameters adjustments, and increase in computational time. The above-listed methods have also shown their advantages in some ways (Mohd Zaihidee, Mekhilef, \& Mubin, 2019), but they suppressed the remarkable property of SMC in terms of simplicity.

A simpler method to enhance SMC performance is by modifying its sliding surface. Previous researchers proposed a few designs, e.g., integral (Song \& Jia, 2016) and nonsingular terminal (Xu, Jiang, Mu, \& Yue, 2015). Fractional order sliding surface design is proposed to construct a fractional order sliding mode controller (FOSMC). Fractional calculus is incorporated in sliding manifold design, where integral and derivative operators with fractional order provide extra degree of freedom that improves the controller's performance compared to integer order SMC (IOSMC). Fractional calculus properties also support in suppressing chattering since they promote slower energy transfer during switching (B. Zhang et al., 2012). FOSMC can be designed using fractional integration (PI) surface (B. Zhang et al., 2012), fractional differentiation (PD) surface (Huang, Li, Teng, \& Liu, 2012), or combination of both, namely, fractional PID surface. In their integer order SMC, Jafarov, Parlakci, and Istefanopulos (2005) have proven that SMC with PID sliding surface has a faster response than SMC with PD sliding surface. Derivative term in sliding surface ensures a more stable system by preventing excessive control effect of the integral action (Li, Wang, \& Gao, 2001).

In this paper, a FOSMC-PID sliding surface is proposed. This sliding surface design combines the advantages of FOSMC with PI and PD sliding surfaces, as well as eliminating their weaknesses in terms of robustness and dynamic performance. Incorporation of fractional calculus in the controller ensures suppression of chattering phenomenon. The effectiveness of the proposed controller was verified using MATLAB/Simulink simulation approach.

\section{FIELD-ORIENTED CONTROL OF PMSM}

In field oriented control of PMSM shown in Figure 1, the mathematical model of a PMSM described in the rotor reference frame is defined in Equations (1)-(4) (B. Zhang et al., 2012), where $u_{d}, u_{q}$ are the d,q-axis stator voltages respectively; $i_{d}, i_{q}$ are the d,q-axis stator currents, respectively; $L_{d}, L_{q}$ are the d,q-axis stator inductances ,respectively; $T_{e}$ is the electric torque; $I_{d f}$ is the equivalent d-axis magnetizing current; $L_{m d}$ is the d-axis mutual inductance; $n_{p}$ is the pole pair; $\omega_{f}$ is the inverter frequency, and $\omega_{r}$ is the rotor speed. 


$$
\begin{aligned}
& u_{d}=R_{s} i_{d}+\dot{\lambda}_{d}-\omega_{f} \lambda_{q} \\
& u_{q}=R_{s} i_{q}+\dot{\lambda}_{q}+\omega_{f} \lambda_{d} \\
& T_{e}=1.5 n_{p}\left(L_{m d} I_{d f} i_{q}+\left(L_{d}-L_{q}\right) i_{d} i_{q}\right) \\
& \omega_{f}=n_{p} \omega_{r},
\end{aligned}
$$

$\lambda_{d}, \lambda_{q}$ are the d,q-axis stator flux linkages, which are defined in Equations (5) and (6). Motor dynamics is described in Equation (7), where $J$ is the moment of inertia, $B_{m}$ is the viscous friction coefficient, and $T_{L}$ is the load torque. Constant torque angle control strategy is used in this work; hence, d-axis stator current command, $i_{d}$, is set to be zero. Simplified electromagnetic torque in Equation (9) is obtained. State equation of the servo drive is obtained as per Equation (11), by equating both Equations (7) and (9).

$$
\begin{aligned}
& \lambda_{q}=L_{q} i_{q} \\
& \lambda_{d}=L_{d} i_{d}+L_{m d} I_{d f} \\
& T_{e}=J \dot{\omega}_{r}+B_{m} \omega_{r}+T_{L} \\
& T_{e}=1.5 n_{p}\left(L_{m d} I_{d f} i_{q}\right) \\
& T_{e}=k_{t} i_{q} \\
& k_{t}=1.5 n_{p} L_{m d} I_{d f} \\
& \dot{\omega}_{r}=-\frac{B_{m}}{J} \omega_{r}+\frac{k_{t}}{J} i_{q}-\frac{T_{L}}{J}
\end{aligned}
$$

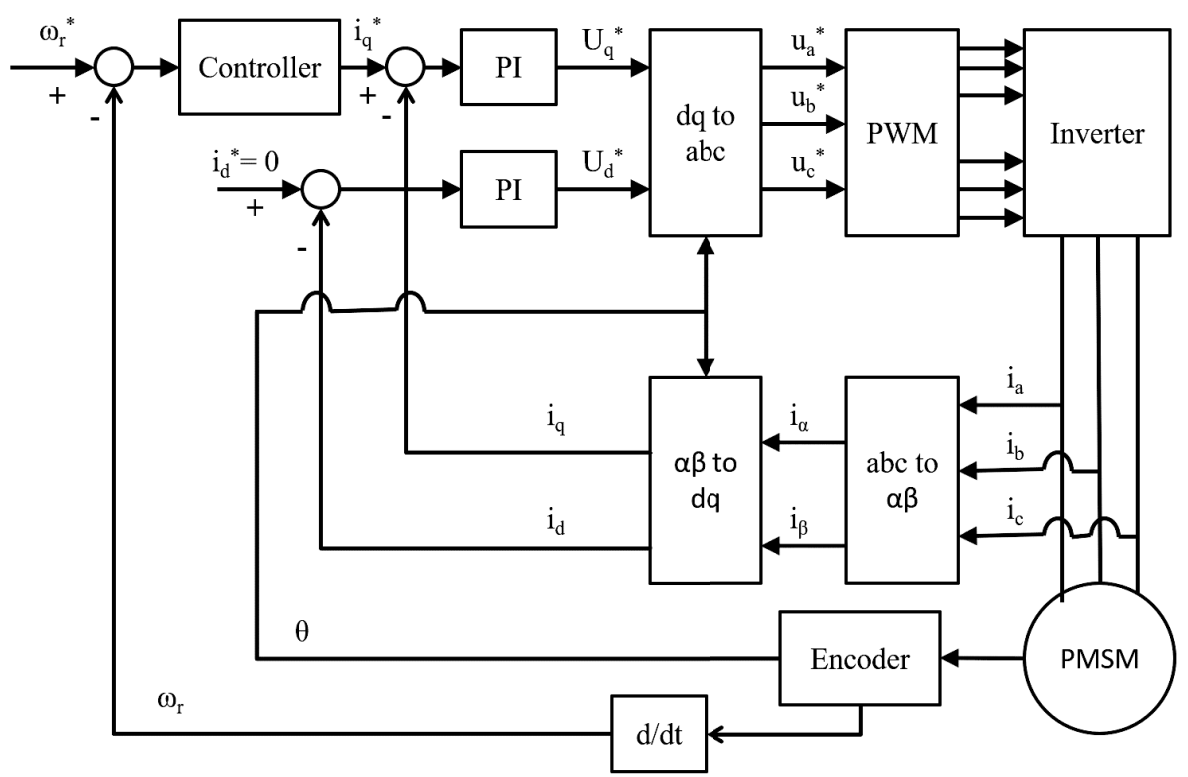

Figure 1. Field-oriented control of PMSM. 


\section{FRACTIONAL CALCULUS}

Although fractional calculus has been theoretically introduced since three centuries ago, it has only been applied for science and engineering applications in recent decades (Efe, 2011). Traditional integer order calculus is generalized to the non-integer order. Fractional order term is more stable than the integer order term due to its data storage properties (Huang, Cui, Shi, Li, \& Xiang, 2014; B. Zhang et al., 2012). Equation (12) defines the fundamental operator of fractional calculus, ${ }_{a} D_{t}^{r}$, where $a$ and $t$ are the limits of the operation. The order of operation, $r$ is generally $r \in \mathcal{R}$ (Ying, Yang Quan, Hyo-Sung, \& Youguo, 2009). Fractional calculus is commonly defined using the GrunwaldLetnikov definition, the Riemann-Liouville (RL) definition and the Caputo definition.

$$
{ }_{a} D_{t}^{r}=\left\{\begin{array}{cc}
\frac{d^{r}}{d t^{r}} & \text { for } r>0 . \\
1 & \text { for } r=0 . \\
\int_{a}^{t}(d \tau)^{-r} & \text { for } r<0 .
\end{array}\right.
$$

In depth understanding of fractional calculus in terms of its main properties (Ying et al., 2009) and comparison with integer order calculus can be found in previous literatures (Podlubny, 2002). Fractional calculus has been incorporated for various applications such as fractional PID $\left(\mathrm{PI}^{\lambda} \mathrm{D}^{\mu}\right)$ controllers (Hongsheng, Ying, \& Yang Quan, 2010; Lanusse, Oustaloup, \& Sabatier, 2014; B. T. Zhang \& Pi, 2012), fractional adaptive controllers (Efe, 2008; Ladaci \& Charef, 2006), fractional order sliding mode observer (Mujumdar, Tamhane, \& Kurode, 2015), fractional order compensators (Ying Luo, Chen, Ahn, \& Pi, 2010; Y. Luo, Chen, Ahn, \& Pi, 2012; Salehtavazoei \& Tavakoli-Kakhki, 2014; Ying et al., 2009), and FOSMC (Abdelhamid, Bouden, \& Boulkroune, 2014; Calderón, Vinagre, \& Feliu, 2006; Delavari, Ghaderi, Ranjbar, \& Momani, 2010; Mujumdar et al., 2015).

\section{FOSMC-PID FOR SPEED CONTROL OF PMSM}

In the FOSMC-PID speed controller, the reference speed, $\omega_{r}^{*}$ should be tracked asymptotically based on speed tracking error, $e(t)$, as defined in Equation (13). Equation (14) defines its derivative, where $a=\frac{B_{m}}{J}, b=\frac{k_{t}}{J}, c=\frac{T_{L}}{J}$. $\phi(t)$ is defined in Equation (15) and $\delta(t)$ in Equation (16) is bounded lumped uncertainty with $\Delta a, \Delta b, \Delta c$ as the timevarying value of the system parameters. Output of the SMC is regarded as q-axis stator current command, $i_{q}^{*}$ and is fed to the inner q-axis current controller as input.

$$
\begin{aligned}
& e(t)=\omega_{r}^{*}(t)-\omega_{r}(t) \\
& \dot{e}(t)=-a e(t)-b i_{q}^{*}(t)+\phi(t)+\delta(t) \\
& \phi(t)=a \omega_{r}^{*}(t)+c(t)+\dot{\omega}_{r}^{*}(t) \\
& \delta(t)=\Delta a \omega_{r}(t)-\Delta b i_{q}^{*}(t)+\Delta c(t)
\end{aligned}
$$

In this work, a fractional PID $\left(P I^{\alpha} D^{\beta}\right)$ sliding surface as defined in Equation (17) is proposed for the speed controller. ${ }_{0} D_{t}^{-\alpha}($.$) is a fractional integration with order \alpha$ and ${ }_{0} D_{t}^{\beta}($.$) is a fractional differentiation with order \beta$. Constant and proportional rate reaching law in Equation (18) is used, where $w, k_{s} \in \mathcal{R}^{+}$.

$$
\begin{aligned}
& s(t)=k_{p} e(t)+k_{i 0} D_{t}^{-\alpha} e(t)+k_{d 0} D_{t}^{\beta} e(t) \\
& \dot{s}=-w s-k_{s} \operatorname{sign}(s)
\end{aligned}
$$


Equivalent control law determines the output of the controller. Firstly, the derivative of the sliding surface, $\dot{s}(t)$ is constructed as in Equations (19) and (20). Equating Equation (20) to Equation (18) and considering ideal condition where the lumped uncertainty is ignored $(\delta(t)=0)$, the equivalent control law in Equation (21) is obtained. For current controllers in the inner loop, conventional PI control algorithm is used to reduce controller's complexity.

$$
\begin{aligned}
& \dot{s}=\frac{d}{d t}\left(k_{p} e(t)+k_{i 0} D_{t}^{-\alpha} e(t)+k_{d 0} D_{t}^{\beta} e(t)\right) \\
& \dot{s}=k_{i 0} D_{t}^{1-\alpha} e(t)+k_{d 0} D_{t}^{\beta+1} e(t)+k_{p}\left(-a e(t)-b i_{q}^{*}(t)+\phi(t)\right) \\
& i_{q}^{*}(t)=\frac{1}{b k_{p}}\left[\begin{array}{l}
k_{i 0} D_{t}^{1-\alpha} e(t)+k_{d 0} D_{t}^{\beta+1} e(t)+(w-a) k_{p} e(t)+k_{p} \phi(t)+w k_{i 0} D_{t}^{-\alpha} e(t) \\
+w k_{d 0} D_{t}^{\beta} e(t)+k_{s} \operatorname{sign}(s)
\end{array}\right]
\end{aligned}
$$

For the designed FOSMC-PID speed controller, by using Lyapunov stability theorem, reaching condition proven to be satisfied if $\frac{k_{s}}{k_{p}}>\Omega$. Furthermore, system convergence to sliding surface is guaranteed when Equation (22) is satisfied (B. Zhang et al., 2012). For positive $k_{p}, k_{i}$ and $k_{d}$, the system is stable during sliding condition. Stability analysis of the proposed system is detailed in (Zaihidee, Mekhilef, \& Mubin, 2018).

$$
t \geq t_{0}-\frac{1}{w} \ln \frac{k_{s}}{w\left|s\left(t_{0}\right)\right|+k_{s}}
$$

\section{SIMULATION RESULTS}

The superiorities of the proposed FOSMC-PID controller were demonstrated through simulations in MATLAB/ Simulink environment with PMSM parameters indicated in Table 1. For comparison purposes, simulations of a conventional SMC, a FOSMC-PI controller, and a FOSMC-PD controller were also executed. The control objective is to drive the motor to a reference speed $(500 \mathrm{rpm})$ with applied disturbance load torque, $T_{L}$ of $2 \mathrm{Nm}$ after $0.5 \mathrm{~s}$. The PI parameters of d-axis and q-axis current loops are $k_{p, d}=25.44, k_{i, d}=4800$ and $k_{p, q}=27, k_{i, q}=4800$, respectively. To have a fair comparison, the switching gain, $k_{s}$ for the proposed controller and other controllers in comparison is selected to be the same with $k_{s}=8$.

Table 1. Parameters of PMSM.

\begin{tabular}{|c|c|}
\hline Parameter & Value \\
\hline Rated power, $\mathrm{P}_{\mathrm{N}} \mathrm{P}_{\mathrm{N}}[\mathrm{kW}]$ & 1.93 \\
\hline Stator resistance, $\mathrm{R}_{\mathrm{S}}[\Omega]$ & 1.2 \\
\hline Stator d-axis inductance, $\mathrm{L}_{\mathrm{d}}[\mathrm{mH}]$ & 6.35 \\
\hline Stator q-axis inductance, $\mathrm{L}_{\mathrm{q}}[\mathrm{mH}]$ & 6.75 \\
\hline Rotor flux linkage, $\Psi_{\mathrm{f}}[\mathrm{Wb}]$ & 0.15 \\
\hline Moment of inertia, $\mathrm{J}\left[\mathrm{kg} \cdot \mathrm{m}^{2}\right]$ & $2.31 \times 10^{-4}$ \\
\hline Number of pole pairs, $\mathrm{n}_{\mathrm{p}}$ & 4 \\
\hline
\end{tabular}

First, the controller's performance was compared with the performance of a conventional SMC. The results in Fig. 2(a) prove that the FOSMC control scheme has shorter settling time and less overshoot compared to conventional SMC control scheme. Fig. 2(b) shows that the proposed control method experienced less speed drop and has a better disturbance rejection ability when sudden load disturbance is applied. 
FOSMC-PID control scheme resulted in better step response with less overshoot than FOSMC-PI, as shown in Fig. 3(a). FOSMC-PD control method resulted in no overshoot but has a settling time of about 10 times higher that FOSMC-PID. Applied load torque causes system with FOSMC-PI and FOSMC-PD to experience more speed dip (Fig. 3b), compared to only 1\% in FOSMC-PID system. Speed recovery occurs faster in system with FOSMC-PID than system with FOSMC-PI. FOSMC-PD suffers from a larger steady state error compared to both FOSMC-PID and FOSMC-PI.

Torque ripple of FOSMC-PID and FOSMC-PD are almost equal. However, the torque ripple of FOSMC-PI is slightly higher than the torque ripple of FOSMC-PID, as shown in Figure 4. Figure 5 shows the comparison of q-axis current ripple between FOSMC-PID and FOSMC-PI control scheme. Results show that FOSMC-PID system experience less ripple compared to FOSMC-PI, indicating that the proposed sliding surface has successfully reduced the chattering effect of the controller's output.

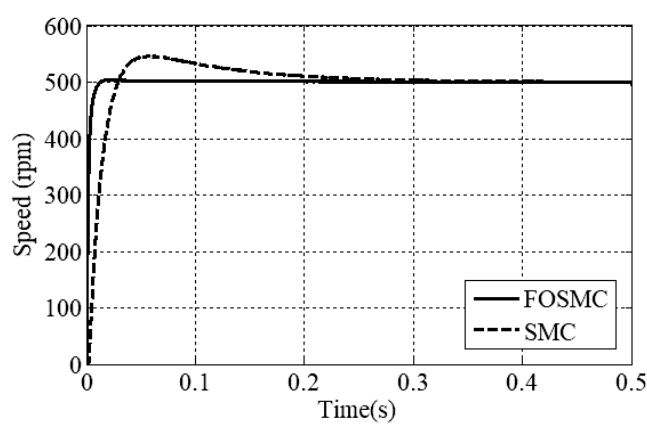

(a)

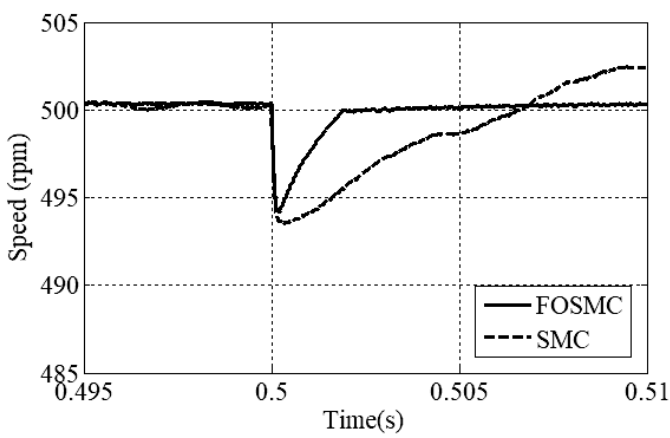

(b)

Figure 2. Speed responses of PMSM system using FOSMC and SMC control scheme. (a) without load. (b) when sudden load is applied.

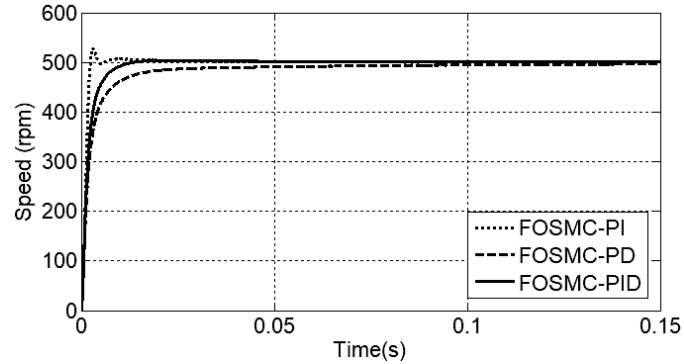

(a)

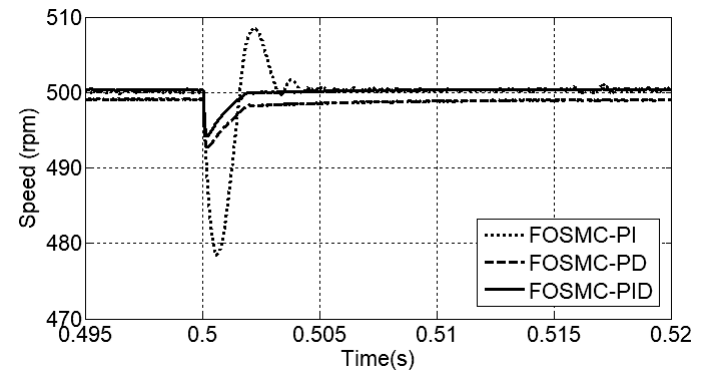

(b)

Figure 3. Speed responses of PMSM system using FOSMC-PI, FOSMC-PD and FOSMC-PID control scheme.

(a) without load. (b) when sudden load is applied (simulation).

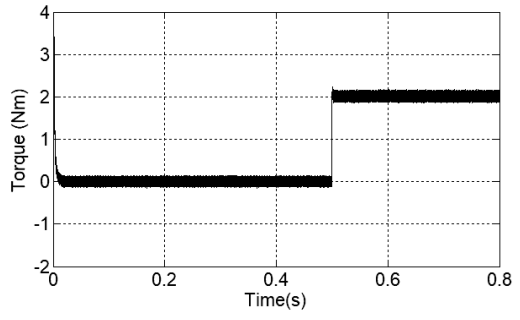

(a)

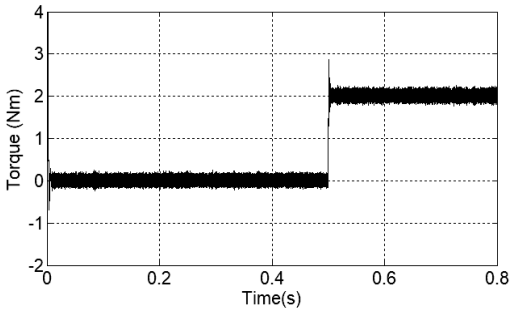

(b)

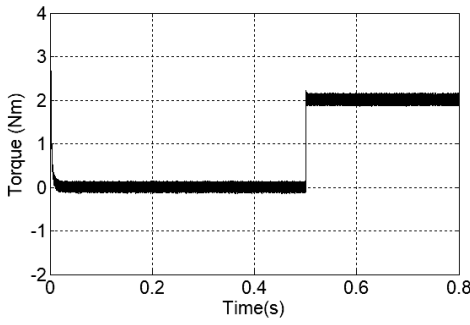

(c)

Figure 4. Torque response of PMSM system with different control schemes (a) FOSMC-PID.

(b) FOSMC-PI. (c) FOSMC-PD. 


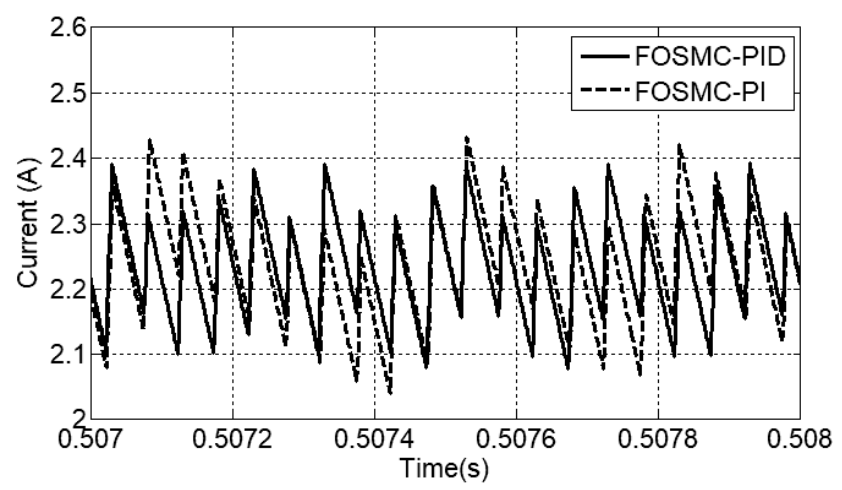

Figure 5. q-axis current ripple of FOSMC-PID and FOSMC-PI control scheme.

The overall simulation results demonstrated that the proposed control method improved the dynamic performance and robustness of the PMSM speed regulation system and suppressed the chattering phenomenon in the sliding mode control.

\section{EXPERIMENTAL RESULTS}

Simulation results are then validated using PMSM drive prototype. In the experimental setup, as shown in Figure 6, the PMSM is run by a 3-phase voltage source inverter. Controller dSpace DS1104 is used, where signal monitoring can be done through ControlDesk software. Programmable hysteresis brake gives the required load to the motor. Torque and speed are measured using torque and speed transducer. The setup also consists of auxiliary circuits designed for current measurement and encoder data interface to controller.

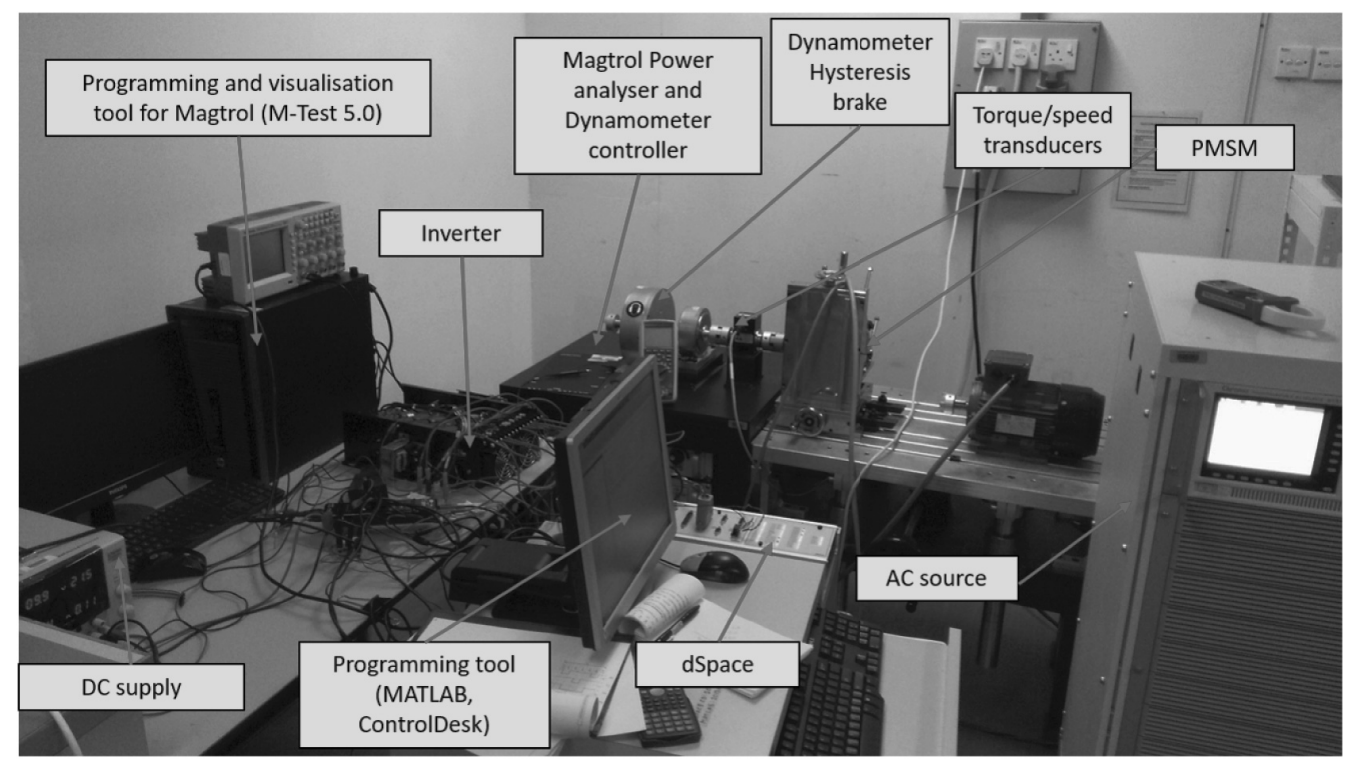

Figure 6. PMSM drive prototype.

This experimental validation is an extension of (Zaihidee, Mekhilef, \& Mubin, 2019), where performance comparison between FOSMC and SMC has been detailed. In this work, performance of the proposed FOSMC-PID is compared with FOSMC-PI and FOSMC-PD. Fig. 7(a) shows step response of the speed controller when investigated with speed reference of $250 \mathrm{rpm}$. FOSMC-PID and FOSMC-PI settled at about similar time, but FOSMC-PI experiences 
a slightly higher overshoot than FOSMC-PID. For FOSMC-PD, it takes about $67 \%$ higher settling time. A load torque of $1 \mathrm{Nm}$ is applied to the system to validate anti-disturbance properties of the proposed controller. In system with FOSMC-PID, speed drop of only $29.32 \%$ is recorded, as shown in Fig. 7(b). FOSMC-PI and FOSMC-PD systems experience speed drop of $7.76 \%$ and $12.64 \%$ higher, respectively. In addition, system with FOSMC-PD controller has higher steady-state error than other systems in comparison. The overall experimental results demonstrated that the proposed control method improved the dynamic performance and robustness of the PMSM speed regulation system.

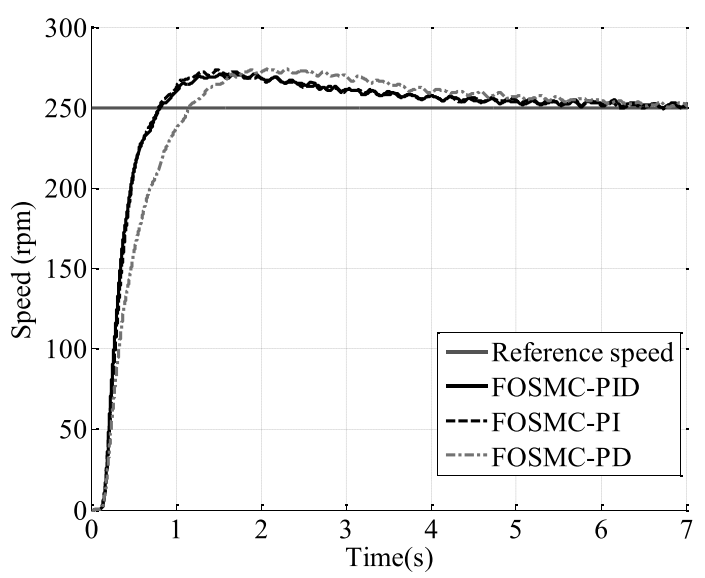

(a)

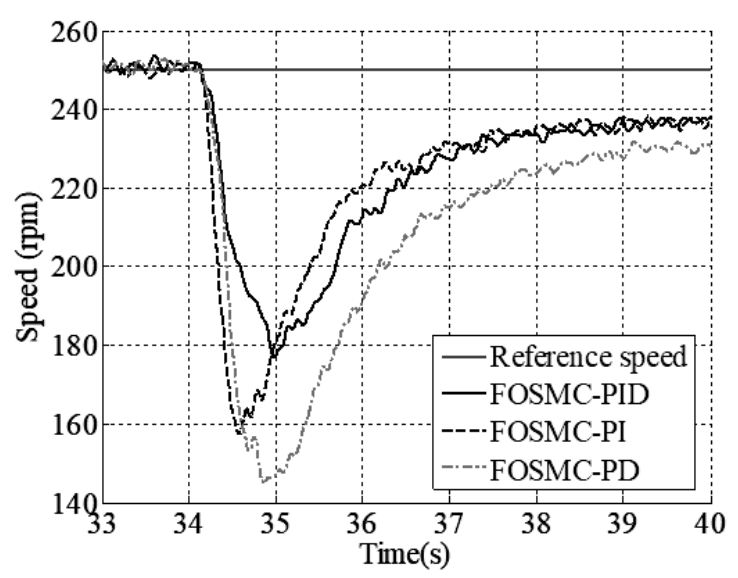

(b)

Figure 7. Speed responses of PMSM system using FOSMC-PI, FOSMC-PD and FOSMC-PID control scheme. (a) without load. (b) when sudden load is applied (experimental).

\section{CONCLUSION}

FOSMC-PID PMSM speed controller is proposed in this work. Fractional integration and differentiation terms are used to design the sliding manifold. Simulation and experimental results show superiorities of proposed controller against IOSMC with better speed response and better robustness during load disturbance. Furthermore, chattering phenomenon is also reduced when the integer calculus is replaced with fractional calculus.

\section{REFERENCES}

Abdelhamid, D., Bouden, T., \& Boulkroune, A. (2014). Design of Fractional-order Sliding Mode Controller (FSMC) for a class of Fractional-order Non-linear Commensurate Systems using a Particle Swarm Optimization (PSO) Algorithm. Journal of Control Engineering and Applied Informatics, 16(3): 46-55.

Calderón, A.J., Vinagre, B.M., \& Feliu, V. (2006). Fractional order control strategies for power electronic buck converters. Signal Processing, 86(10): 2803-2819. doi:http://dx.doi.org/10.1016/j.sigpro.2006.02.022

Delavari, H., Ghaderi, R., Ranjbar, A., \& Momani, S. (2010). Fuzzy fractional order sliding mode controller for nonlinear systems. Communications in Nonlinear Science and Numerical Simulation, 15(4): 963-978. doi:http://dx.doi.org/10.1016/j. cnsns.2009.05.025

Efe, M.O. (2008). Fractional Fuzzy Adaptive Sliding-Mode Control of a 2-DOF Direct-Drive Robot Arm. IEEE Transactions on Systems, Man, and Cybernetics, Part B: Cybernetics, 38(6): 1561-1570. doi:10.1109/TSMCB.2008.928227

Efe, M.O. (2011). Fractional Order Systems in Industrial Automation - A Survey. IEEE Transactions on Industrial Informatics, 7(4): 582-591. doi:10.1109/TII.2011.2166775

Errouissi, R., Ouhrouche, M., Wen-Hua, C., \& Trzynadlowski, A.M. (2012). Robust Nonlinear Predictive Controller for Permanent-Magnet Synchronous Motors With an Optimized Cost Function. IEEE Transactions on Industrial Electronics, 59(7): 2849-2858. doi:10.1109/TIE.2011.2157276 
Han Ho, C., \& Jin-Woo, J. (2013). Discrete-Time Fuzzy Speed Regulator Design for PM Synchronous Motor. IEEE Transactions on Industrial Electronics, 60(2): 600-607. doi:10.1109/TIE.2012.2205361

Hongsheng, L., Ying, L., \& Yang Quan, C. (2010). A Fractional Order Proportional and Derivative (FOPD) Motion Controller: Tuning Rule and Experiments. IEEE Transactions on Control Systems Technology, 18(2): 516-520. doi:10.1109/ TCST.2009.2019120

Hsien, T.L., Sun, Y.Y., \& Tsai, M.C. (1997). Ho control for a sensorless permanent-magnet synchronous drive. IEEE Proceedings on Electric Power Applications, 144(3): 173-181. doi:10.1049/ip-epa:19970988

Huang, J., Cui, L., Shi, X., Li, H., \& Xiang, Z. (2014). Composite integral sliding mode control for PMSM. Paper presented at the 33rd Chinese Control Conference (CCC), Nanjing, China.

Huang, J., Li, H., Teng, F., \& Liu, D. (2012). Fractional order sliding mode controller for the speed control of a permanent magnet synchronous motor. Paper presented at the 24th Chinese Control and Decision Conference (CCDC).

Jafarov, E.M., Parlakci, M.N.A., \& Istefanopulos, Y. (2005). A new variable structure PID-controller design for robot manipulators. IEEE Transactions on Control Systems Technology, 13(1): 122-130. doi:10.1109/TCST.2004.838558

Ladaci, S., \& Charef, A. (2006). On Fractional Adaptive Control. Nonlinear Dynamics, 43(4): 365-378. doi:10.1007/s11071-0060159-x

Lanusse, P., Oustaloup, A., \& Sabatier, J. (2014). Robust factional order PID controllers: The first generation CRONE CSD approach. Paper presented at the International Conference on Fractional Differentiation and Its Applications (ICFDA), Catania.

Li, M., Wang, F., \& Gao, F. (2001). PID-based sliding mode controller for nonlinear processes. Industrial and Engineering Chemistry Research, 40(12): 2660-2667.

Luo, Y., Chen, Y., Ahn, H.S., \& Pi, Y. (2010). Fractional order robust control for cogging effect compensation in PMSM position servo systems: Stability analysis and experiments. Control Engineering Practice, 18(9): 1022-1036. doi:http://dx.doi. org/10.1016/j.conengprac.2010.05.005

Luo, Y., Chen, Y.Q., Ahn, H.S., \& Pi, Y.G. (2012). Fractional Order Periodic Adaptive Learning Compensation for StateDependent Periodic Disturbance. IEEE Transactions on Control Systems Technology, 20(2): 465-472. doi:10.1109/ TCST.2011.2117426

Mohd Zaihidee, F., Mekhilef, S., \& Mubin, M. (2019). Robust Speed Control of PMSM Using Sliding Mode Control (SMC)—A Review. Energies, 12(9): 1669. Retrieved from https://www.mdpi.com/1996-1073/12/9/1669

Mujumdar, A., Tamhane, B., \& Kurode, S. (2015). Observer-Based Sliding Mode Control for a Class of Noncommensurate FractionalOrder Systems. IEEE/ASME Transactions on Mechatronics, 20(5): 2504-2512. doi:10.1109/TMECH.2014.2386914

Podlubny, I. (2002). Geometric and Physical Interpretation of Fractional Integration and Fractional Differentiation. Fractional Calculus and Applied Analysis, 5(4): 367-386.

Salehtavazoei, M., \& Tavakoli-Kakhki, M. (2014). Compensation by fractional-order phase-lead/lag compensators. IET Control Theory \& Applications, 8(5): 319-329. doi:10.1049/iet-cta.2013.0138

Shihua, L., Mingming, Z., \& Xinghuo, Y. (2013). Design and Implementation of Terminal Sliding Mode Control Method for PMSM Speed Regulation System. IEEE Transactions on Industrial Informatics, 9(4): 1879-1891. doi:10.1109/TII.2012.2226896

Shihua Li, Kai Zong, \& Huixian Liu. (2011). A composite speed controller based on a second-order model of permanent magnet synchronous motor system. Transactions of the Institute of Measurement and Control, 33(5): 522-541. doi: $10.1177 / 0142331210371814$

Song, Q., \& Jia, C. (2016). Robust Speed Controller Design for Permanent Magnet Synchronous Motor Drives Based on Sliding Mode Control. Energy Procedia, 88: 867-873. doi:http://dx.doi.org/10.1016/j.egypro.2016.06.102

Su, Y.X., Zheng, C.H., \& Duan, B.Y. (2005). Automatic disturbances rejection controller for precise motion control of permanentmagnet synchronous motors. IEEE Transactions on Industrial Electronics, 52(3): 814-823. doi:10.1109/TIE.2005.847583

Utkin, V.I. (1993). Sliding mode control design principles and applications to electric drives. IEEE Transactions on Industrial Electronics, 40(1): 23-36. doi:10.1109/41.184818 
Vu, N.T.T., Choi, H.H., \& Jung, J.W. (2012). Certainty equivalence adaptive speed controller for permanent magnet synchronous motor. Mechatronics, 22(6): 811-818. doi:http://dx.doi.org/10.1016/j.mechatronics.2012.04.007

Wang, A., Jia, X., \& Dong, S. (2013). A New Exponential Reaching Law of Sliding Mode Control to Improve Performance of Permanent Magnet Synchronous Motor. IEEE Transactions on Magnetics, 49(5): 2409-2412. doi:10.1109/ TMAG.2013.2240666

Xiaoguang, Z., Lizhi, S., Ke, Z., \& Li, S. (2013). Nonlinear Speed Control for PMSM System Using Sliding-Mode Control and Disturbance Compensation Techniques. IEEE Transactions on Power Electronics, 28(3): 1358-1365. doi:10.1109/ TPEL.2012.2206610

Xu, W., Jiang, Y., \& Mu, C. (2016). Novel Composite Sliding Mode Control for PMSM Drive System Based on Disturbance Observer. IEEE Transactions on Applied Superconductivity, 26(7): 1-5. doi:10.1109/TASC.2016.2611623

Xu, W., Jiang, Y., Mu, C., \& Yue, H. (2015). Nonsingular terminal sliding mode control for the speed regulation of permanent magnet synchronous motor with parameter uncertainties. Paper presented at the 41st Annual Conference of the IEEE Industrial Electronics Society (IECON).

Xu, W., Junejo, A.K., Liu, Y., \& Islam, M.R. (2019). Improved Continuous Fast Terminal Sliding Mode Control with Extended State Observer for Speed Regulation of PMSM Drive System. IEEE Transactions on Vehicular Technology, 68(11): 10465 - 10476. doi:10.1109/TVT.2019.2926316

Ying, L., Yang Quan, C., Hyo-Sung, A., \& Youguo, P. (2009). Fractional order periodic adaptive learning compensation for cogging effect in PMSM position servo system. Paper presented at the American Control Conference (ACC), St. Louis, Missouri, USA.

Zaihidee, F.M., Mekhilef, S., \& Mubin, M. (2018). Fractional Order SMC for Speed Control of PMSM. Paper presented at the 2018 International Electrical Engineering Congress (iEECON).

Zaihidee, F.M., Mekhilef, S., \& Mubin, M. (2019). Application of Fractional Order Sliding Mode Control for Speed Control of Permanent Magnet Synchronous Motor. IEEE Access, 7: 101765-101774. doi:10.1109/ACCESS.2019.2931324

Zhang, B., Pi, Y., \& Luo, Y. (2012). Fractional order sliding-mode control based on parameters auto-tuning for velocity control of permanent magnet synchronous motor. ISA Transactions, 51(5): 649-656. doi:http://dx.doi.org/10.1016/j.isatra.2012.04.006

Zhang, B.T., \& Pi, Y. (2012). Robust fractional order proportion-plus-differential controller based on fuzzy inference for permanent magnet synchronous motor. IET Control Theory \& Applications, 6(6): 829-837. doi:10.1049/iet-cta.2011.0412

Zhang, X., Zhao, K., \& Sun, L. (2011). A PMSM sliding mode control system based on a novel reaching law. Paper presented at the International Conference on Electrical Machines and Systems (ICEMS).

Zhou, J., \& Wang, Y. (2002). Adaptive backstepping speed controller design for a permanent magnet synchronous motor. IEE Proceedings - Electric Power Applications, 149(2): 165-172. doi:10.1049/ip-epa:20020187 